\title{
Constantino y su relación personal con el cristianismo: de la piedad tradicional a la conversión ${ }^{1}$
}

\author{
Esteban MORENo RESANO \\ Universidad de Zaragoza \\ estmores@unizar.es
}

\section{RESUMEN}

La adhesión de Constantino al cristianismo fue un largo proceso en el que mediaron motivaciones personales, además de factores culturales y políticos. Observó los cultos tradicionales y no se reconoció cristiano hasta el año 314, en la carta dirigida a los obispos reunidos en Arelate. A partir del año 324, después de la derrota de Licinio, manifestó su fe en un solo Dios verdadero en distintos textos oficiales. Decidió recibir el bautismo poco antes de morir, en 337, parece que buscando la curación de su enfermedad. Su concepción del cristianismo fue la de una religión utilitaria, que le ofreció protección en la guerra y garantizó su autoridad en tiempos de paz con el apoyo de la Iglesia.

Palabras clave: Constantino, conversión, cultos tradicionales, cristianismo, Iglesia primitiva.

\section{Constantine and His Personal Relation with Christianity: from Heathen Piety to Conversion}

\begin{abstract}
Constantine's adherence to Christianity was a long process conditioned by personal motivations, as well as cultural and political factors. He observed the heathen cults and he did not recognize himself as a christian until the year 314, in his letter to the bishops met in Arelate. Since 324, after the defeat of Licinius, he declared his faith in the One and Only True God in different official texts. He resolved to receive the baptism a few days before his death, in 337, perhaps in the hope of healing from his illness. His concept of Christianity was the one of an utilitarian religion, that offered him protection in war and guaranteed his authority in peace with the support of the Church.
\end{abstract}

Keywords: Constantine, conversion, heathen cults, Christianity, Early Church.

${ }^{1}$ Este trabajo ha sido realizado gracias a la concesión de un Contrato de Investigación dentro del Subprograma "Ramón y Cajal" (Ministerio de Economía y Competitividad), y se inscribe dentro del Proyecto de Investigación HAR2008-4355/HIST, financiado por el Ministerio de Economía y Competitividad, y del Grupo Hiberus, subvencionado por el Gobierno de Aragón. 
SUMARIO: 1. Introducción. 2. Los distintos conceptos de "conversión". 3. Constantino y el cristianismo antes de 306. 4. El período de 306-312. 5. La guerra contra Majencio y la diarquía (312-324). 6. La monarquía constantiniana (324-337). 7. El bautismo de Constantino. 8. Conclusiones.

FECHA DE RECEPCIÓN: 03 DE 06 DE 2013 FECHA DE ACEPTACIÓN: 05 DE 07 DE 2013

\section{INTRODUCCIÓN}

Más de siglo y medio después de la publicación de la obra de Jakob Burckhardt Die Zeit Constantins des Großen (Basel, 1853), continúa abierta la llamada «cuestión constantiniana», esto es, el debate sobre la relación personal de Constantino con el cristianismo. El historiador suizo cuestionaba la sinceridad de la conversión del emperador, suponiendo que su cambio de religión obedecía a razones de índole pragmática. Desde ese momento, los autores que han tratado este particular se han alineado en dos sentidos: o bien han continuado defendiendo su naturaleza interesada o bien han procurado argumentos a favor de su honesta profesión de fe cristiana ${ }^{2}$. Antes de la Segunda Guerra Mundial, prevaleció la primera de las tendencias, desarrollada por Schwartz, Piganiol y Grégoire ${ }^{3}$. Después de la contienda, sin embargo, un grupo de historiadores de la escuela académica germánica defendieron que el emperador había abrazado el cristianismo por convicciones personales, aunque para ello tuvo en cuenta las importantes consecuencias que tendría este hecho en el orden institucional ${ }^{4}$. Este posicionamiento ante la «cuestión constantiniana» no fue compartido por Kraft, que veía en la conversión del emperador un acomodo a los cambios religiosos de su época ${ }^{5}$. Por el contrario, los estudiosos anglosajones de las décadas siguientes (desde finales de los Sesenta hasta los Ochenta) advirtieron en la conversión de Constantino tanto intereses políticos como un innegable afecto personal hacia el cristianismo ${ }^{6}$. Entretanto, otros investigadores hicieron acopio de argumentos en apoyo de las razones

\footnotetext{
${ }^{2}$ Véase sobre las distintas opiniones: N. H. Baynes, Constantine the Great and the Christian Church, London, 1930; S. Calderone, "Letteratura costantiniana e "conversione" di Costantino», Costantino il Grande dall 'Antichità all'Umanesimo. Colloquio sul Cristianesimo nel mondo antico. Macerata, 18-20 dicembre 1990, I, G. Bonamente y F. Fusco, eds., Macerata, 1993, pp. 231-252; F. Braschi, «La “conversione” di Costantino. Riflessioni a partire dai criteri di lettura delle fonti antiche», Scuola Cattolica 135 (2007), pp. 115-149.

${ }^{3}$ E. Schwartz, Kaiser Konstantin und die christliche Kirche: Fünf Vorträge, Leipzig, 1913; A. Piganiol, L'empereur Constantin, Paris, 1932; H. Grégoire, «Eusèbe n'est pas l'auteur de la "Vita Constantini" dans sa forme actuelle et Constantin n'est pas converti en 312», Byzantion 13 (1938), pp. 561-583.

${ }^{4}$ A. Alföldi, The Conversion of Constantine and the Pagan Rome, Oxford, 1948; H. Dörries, Das Selbstzeugnis Kaiser Konstantins, Göttingen, 1953; A. Eberhardt, «Constantin des Großen Religionspolitik und Gesetzgebung», Zeitschrift der Savigny-Stiftung für Rechtsgeschichte (Romanistische Abteilung) 72 (1955), pp. 127-190; J. Vogt, «Die konstantinische Frage», Relazioni del X Convegno Internazionale di Scienze Storiche, II, Firenze, 1955, pp. 377-423.

${ }^{5}$ H. Kraft, Kaiser Konstantins religiöse Entwicklung, Tübingen, 1955.

${ }^{6}$ R. MacMullen, Constantine, London, 1969; T. D. Barnes, Constantine and Eusebius, Harvard, 1984; R. MacMullen, Christianizing the Roman Empire, A. D. 100-400, New Haven and London, 1984, esp. pp. 43-51.
} 
esencialmente religiosas de la aceptación del cristianismo por parte de Constantino 7 . La historiografía reciente ha subrayado que las inquietudes religiosas del emperador fueron determinantes en su decisión de hacerse cristiano, aunque mediaran en ella los factores políticos ${ }^{8}$. En los últimos años, además, se ha cuestionado la conveniencia de aplicar el concepto de «conversión» al caso particular de Constantino ${ }^{9}$. El propósito de este trabajo es, por una parte, precisar la evolución de la relación entre la política y las manifestaciones religiosas del emperador, y, por otra, sostener la validez de la noción de «conversión» en relación con Constantino, una vez comprendido el carácter plurivalente de dicho término.

En realidad, las controversias acerca de la actitud del emperador hacia el cristianismo comenzaron ya en la Antigüedad. El acercamiento de Constantino a su nueva fe fue bienvenido por los autores cristianos, hecha la excepción de Jerónimo de Estridón ${ }^{10}$. Pero la actitud de los escritores que observaban los cultos tradicionales fue muy distinta: o rechazaron abiertamente su conversión (casos del emperador Juliano, Libanio y Zósimo), o la ignoraron, como Aurelio Víctor, Eutropio y los anónimos redactores de la Origo Constantini imperatoris y De uita et moribus imperatorum $^{11}$. Juliano fue el primer autor que manifestó una posición crítica hacia la decisión de Constantino de hacerse cristiano. Estas discusiones llegaron a su momento cumbre en el siglo V, como demuestran las obras de Sozomeno y Zósimo, autores que representan dos puntos de vista completamente enfrentados ${ }^{12}$. El problema no radica precisamente en la falta de fuentes, sino en su poco disimulada parcialidad. Los autores cristianos procuran información imprescindible para el conocimiento de la cuestión, aunque alteren e inventen datos, forzando su interpretación con fines apologéticos. La finalidad de sus obras, no en vano, era demostrar que su religión era la única verdadera, a partir de un hecho verificable y aceptado de modo general como era la conversión del emperador ${ }^{13}$. En efecto, al margen de la diversidad de versiones, tan-

\footnotetext{
${ }^{7}$ P. Keresztes, Constantine. A Great Christian Monarch and Apostle, Amsterdam, 1981; Th. G. Elliott, «Constantine's Conversion: Do We Really Need It?», Phoenix 41 (1987), pp. 420-438; Th. G. Elliott, The Christianity of Constantine the Great, Scranton, 1996. Aunque algunos años posterior, en esta línea se inscribe también el trabajo de P. Veyne, Quand notre monde est devenu chrétien (312-394), Paris, 2007 (Cito la traducción castellana: El sueño de Constantino. El fin del Imperio pagano y el nacimiento del mundo cristiano, Barcelona, 2008, pp. 12-15).

${ }^{8}$ Kl. M. Girardet, Die konstantinische Wende. Voraussetzungen und geistige Grundlagen der Religionspolitik Konstantins des Großen, Darmstadt, 2006; R. Van Dam, The Roman Revolution of Constantine, 2007, New York, esp. pp. 5-6, 10-11; T. D. Barnes, Constantine. Dynasty, Religion and Power in the Later Roman Empire, London, 2011; P. Maraval, Constantin. Empereur romain, Empereur chrétien (306-337), Paris, 2011.

${ }^{9}$ S. Calderone, «Letteratura costantiniana ..., pp. 231-252; F. Braschi, «La "conversione” ..., 115-149; C. Buenacasa Pérez, «La "conversión” de Constantino I y su aproximación al cristianismo», Cristianismo y mundo romano. Vy VI ciclos de conferencias sobre el mundo clásico, J. Á. Tamayo Errazquin, ed., Vitoria, 2010, pp. 145-169.

${ }^{10}$ Hieron. Strid., Chron., CCLXXVIII Olymp. XXXI; Ambros. Mediol., De obitu Theod., XL; Rufin. Aquil., $H E, \mathrm{I}, 11$.

${ }^{11}$ Iulian. Caes., Or., X (Caes.), 38 (336ab); Liban., Or. XXX, 6; Zos., II, 29.

12 A. Baldini, «Una confutazione cristiana della versione pagana della conversione di Costantino: ulteriori considerazioni di storiografia», Rivista Storica dell'Antichità 33 (2003), pp. 217-241.

${ }^{13}$ K. Gross-Albenhausen, «Zur christlichen Selbsdarstellung Konstantins», Klio 78 (1998), pp. 171-185, esp. p. 171.
} 
to las fuentes adversas como las favorables al hecho coinciden en recordar que Constantino se hizo cristiano en algún momento de su vida, cuando ya era emperador. De todos modos, la relación de Constantino con el cristianismo, que a menudo se ha denominado simplemente «conversión» (término impreciso y equívoco, por ser polisémico), fue un proceso que contó con distintas fases y adoptó diversas formas ${ }^{14}$. $\mathrm{Su}$ actitud evolucionó desde la observancia de los cultos tradicionales (entre 306 y 312), pasando por un breve período en el que asumía recibir la protección de un dios henoteísta de nombre desconocido (312-314), una tercera etapa en la que reconoció a Cristo como divinidad protectora personal (314-324), seguida de una cuarta época, entre 324 y 337, en la que manifestó su adhesión particular a la fe cristiana, hasta recibir finalmente el bautismo, cuando se hallaba próximo a la muerte, que tuvo lugar en primavera de 337.

\section{LOS DISTINTOS CONCEPTOS DE «CONVERSIÓN»}

La «conversión» (del latín conuersio, que significa «dar la vuelta» o «volver hacia») es un proceso de cambio de modo de vida y de pensamiento, que afecta principalmente a la persona que adopta la determinación de llevarla a cabo, aunque siempre dentro de un marco social que actúa de condicionante ${ }^{15}$. La conversión al cristianismo no sólo supone un cambio de religión desde el punto de vista ritual y de la profesión de unos determinados principios doctrinales: precisa, además, de una completa renovación moral, al adquirir nuevos valores éticos reflejados en el modo de pensar y en la conducta (metánoia), que se concreta en el reconocimiento de la existencia del pecado original, la confesión de las propias culpas y en la expresión de la firme determinación de no volver a pecar. La suma de estas actitudes y actos se resumían en el concepto veterotestamentario del «retorno» a Dios (epistrophé) ${ }^{16}$.

En realidad, la noción de «conversión» al cristianismo, y con ella, la propia identidad de los cristianos, estuvo caracterizada durante buena parte del siglo IV por la indefinición conceptual y jurídica. En efecto, a lo largo de los siglos III y IV era expresada de forma metafórica, como un proceso de transformación personal por medio del

\footnotetext{
14 Sobre su periodización y formas, cfr. R. Van Dam, «The Many Conversions of the Emperor Constantine», Conversion in Late Antiquity and Early Middle Ages: Seeying and Believing, K. Mills y A. Grafton, eds., Rochester, 2003, pp. 127-151; C. Buenacasa Pérez, «La “conversión” ..., pp. 145-169.

${ }^{15} \mathrm{H}$. Inglebert, «Introduction», Le problème de la christianisation du monde antique, H. Inglebert, S. Destephen y Br. Dumézil, eds., Paris, 2010, pp. 7-17, esp. pp. 9-10; É. Wolff, «Le vocabulaire latin de la conversion au christianisme», ibidem, pp. 33-38.

16 Sobre el concepto de «conversión», véanse también: A. D. Nock, Conversion. The Old and the New in Religion form Alexander the Great to Augustine, Harvard, 1935; G. Bardy, La conversion au christianisme durant les premiers siècles, Paris, 1949; P. Aubin, Le problème de la «conversion». Étude sur un thème commun à l'hellénisme et au christianisme des trois premiers siècles, Paris, 1963; Conversion ..., K. Mills y A. Grafton, eds., Rochester, 2003; Cl. Tassin, «Qu'est-ce qu'une “conversion” dans le monde antique», Supplement au Cahier Évangile 158 (2010), pp. 3-11; Br. Dumézil, «Les marqueurs juridiques de la conversion en Occident entre le IVe. et le VIIe. siècle», Le problème ..., pp. 307-318.
} 
conocimiento ${ }^{17}$. El término conuersi aparece por primera vez en un texto legal del año 409, asociado a la práctica del culto, esto es, a los aspectos formales -en concreto, la participación litúrgica-, vinculados al hecho en sí de la conversión ${ }^{18}$. A finales del siglo IV, no había conversión si ésta no se verificaba formalmente, con la profesión de fe y, al menos, la recepción del bautismo ${ }^{19}$. A comienzos de esa misma centuria, se puede afirmar que la «conversión» conocía distintas formas. Entre ellas se pueden distinguir la evangélica o salvífica, la intelectual o existencial, la instrumental o tutelar y la social. De todos modos, las características de cada tipo pueden muy bien aparecer en un mismo caso concreto.

Las «conversiones» evangélicas o salvíficas son las adhesiones al cristianismo que siguen el modelo fijado en el Nuevo Testamento: personas que reciben la revelación cristiana, por lo general, gracias a la acción de predicadores, y que deciden acoger el anuncio de la venida del Reino de Dios conforme a las enseñanzas de Jesús de Nazaret $^{20}$. Este modo de «conversión» aparece reiteradamente en el canon neotestamentario. La «conversión» que puede denominarse filosófica o existencial se daba en personas pertenecientes a círculos intelectuales de tendencia ascética. Lactancio, que fue preceptor de Crispo, hijo de Constantino, describe en De ira Dei (redactado hacia 320) un proceso intelectual de acceso gradual a la verdad ${ }^{21}$. El rétor diferenciaba tres fases en ese camino: distinguir las falsas religiones y rechazar sus cultos; confesar la existencia de un solo Dios, el Supremo, poderoso y providente, Creador y regidor del mundo, y, por último, reconocer a las autoridades religiosas legítimas, que enseñan la religión verdadera (uerus Dei cultus) ${ }^{22}$. Lactancio se expresaba en términos esencialmente intelectuales. Apelaba a una religiosidad nada formalista, a diferencia de la que se realizaba en los templos paganos, con humo (en referencia al sacrificio sangriento) y velas encendidas (Sit nobis Deus non in templis, sed in corde nostro). Y, además, recomendaba apartarse de los honores caducos (caduci honores) y de los compromisos políticos (foedus publicum) ${ }^{23}$. A lo largo del siglo IV se producen distintas conversiones de este tipo, cada una de ellas con características muy personales, como las de Arnobio, Fírmico Materno, Agustín de Hipona y Paulino de Nola ${ }^{24}$.

Sin embargo, otros nuevos cristianos llegaban a reconocer la revelación cristiana por razones no muy distintas por las que antes habían venerado a determinados

\footnotetext{
${ }^{17}$ M. Herrero de Jáuregui, «La conversión como metáfora espacial: una propuesta de aproximación cognitiva al cambio cultural de la Antigüedad tardía», Ilu. Revista de Ciencias de las Religiones 10 (2005), pp. 63-84.

${ }^{18}$ CTh. XVI, 8, 19.

${ }^{19} \mathrm{Br}$. Dumézil, «Les marqueurs ..., pp. 309-310.

${ }^{20}$ R. MacMullen, Christianizing ..., pp. 59-67.

${ }^{21}$ Hieron. Strid., Chron., CCLXXIIII Olymp. XIII.

${ }^{22}$ Lact., De ira Dei, II. Cfr. K1. M. Girardet, Die konstantinische Wende ..., pp. 57-60.

${ }^{23}$ Lact., De ira Dei, XXIII.

${ }^{24}$ Hieron. Strid., Chron., CCLXXVI Olymp. XXI; Firm. Matern., De err. prof. rel., VIII, 4; Aug. Hipp., Conf., VII, 10.8; X, 27; Paul. Nol., Ep., IV, 2, 20-23; XXXVIII, 3, 17-18; XLIII, 3, 13-20; Cfr. R. MacMullen, Christianizing ..., pp. 68-73; N. Baglivi, "Costantino "segno di contraddizione": il suo tempo e le sue maschere», Cristiani nell'Impero romano, P. L. Rovito, ed., Napoli, 2002, pp. 217-268, esp. pp. $236-237$.
} 
dioses. Su concepción de la religión era muy utilitaria. A partir del siglo IV, los cristianos conservaron la costumbre pagana de realizar votos, según consta en cierto número de inscripciones y en algunos cánones antiguos ${ }^{25}$. Este modo de conversión comparte algunas características del evangélico. Baste recordar que multitudes de palestinos buscaban a Jesús para que les curase de sus enfermedades en el Nuevo Testamento.

Pero también existía un modelo de conversión social, que obedecía primordialmente a razones de integración comunitaria. Aunque la «conversión» era una decisión personal, algunos casos hacen pensar en resoluciones colectivas, o, al menos, adoptadas en función de lo que habían hecho otros por razones de acomodo social e institucional. Por citar algunos casos concretos, los vecinos de Orcisto (Frigia), Constancia (Palestina) y Constantina (Fenicia), distritos urbanos dependientes de otras ciudades declararan ser todos cristianos para obtener del emperador la autonomía municipal ${ }^{26}$. También la relativamente rápida difusión del cristianismo entre los soldados a lo largo del siglo IV parece explicarse en virtud de la camaradería que había entre ellos. Este proceso sólo se había iniciado en época de Constantino, cuando las aclamaciones imperiales todavía eran politeístas ${ }^{27}$. Sin embargo, a partir de finales del siglo IV, actos como el juramento en clave cristiana sirvieron para fortalecer la integración corporativa de las tropas dentro del ejército ${ }^{28}$.

Ninguno de los supuestos comentados parece coincidir con el proceso gradual de adhesión al cristianismo de Constantino: ni buscaba la salvación personal, aunque en el momento de bautizarse confesó sus pecados, ni era un intelectual en busca de la verdad, si bien se presentó como tal en la carta a los obispos reunidos en distintos textos oficiales. Nunca se apartó de los honores y funciones públicas, civiles y militares, como proponía Lactancio. Fue un emperador y actuó en calidad de un hombre que debía gestionar la res publica, atento primordialmente a las cuestiones militares y legislativas. Si se hizo cristiano, no fue por seguir una tendencia social. Por el contrario, su cambio de actitud en lo religioso llevó a muchos ciudadanos a acercarse al cristianismo. Constantino mostró su adhesión a esta religión de distintos modos: como emperador-soldado que buscaba una eficaz divinidad protectora, como príncipe-filósofo que reflexiona sobre su vida y forma de ejercer el poder, y, finalmente, lo hizo como un enfermo que buscaba la curación sobrenatura ${ }^{29}$. A la luz de las fuentes, por tanto, Constantino asumió el cristianismo en calidad de religión personal, concebido como un culto en términos tradicionales, que le protegía y procuraba la victoria mili-

\footnotetext{
${ }^{25}$ CIL V, 1600; VIII, 11113, 23921; IX, 276; Const. Apost., VIII, 30; IX, 23. Cfr. R. MacMullen, Christianizing ..., pp. 52-58; P. Veyne, Quand ..., pp. 140-141.

${ }^{26}$ CIL III, Suppl. I, 7000 (=ILS, II 1, 6091) (Orcisto); Euseb. Caes., VC, IV, 38-39 (Constancia y Constantina).

${ }^{27}$ CTh. VII, 20, 2: (Constantinus Augustus) cum introisset principia et salutatus esset a praefectis et tribunis et uiris eminentissimis, adclamatum est: Auguste Constantine, dii te nobis seruent (...). (320).

${ }^{28}$ Veg., De re militari, II, 5. Cfr. J. F. Shean, Soldiering for God. Christianity and the Roman Army, Leiden, 2010, pp. 284-286. Sobre la presencia de cristianos en el ejército de Constantino, cfr. J. Fernández Ubiña, Cristianos y militares. La Iglesia antigua ante el ejército y la guerra, Granada, 2000, pp. 476-482.

${ }^{29}$ R. Van Dam, «The Many Conversions ..., pp. 127-151.
} 
tar y garantizaba su autoridad imperial ${ }^{30}$. Hizo profesión de fe en 324 y 325 , en una serie de documentos imperiales, pero no reconoció su condición pecadora ni sus culpas hasta el momento previo a su bautismo. Constantino abrazó el cristianismo de modo paulatino, en función de su asimilación de la doctrina cristiana y de los compromisos que fue adquiriendo con el clero que la administraba. Su propia condición de emperador hizo que fuera el suyo un caso muy excepcional.

\section{CONSTANTINO Y EL CRISTIANISMO ANTES DE 306}

Los autores cristianos antiguos ya plantearon que Constantino había conocido el cristianismo en el seno de su familia. Lactancio, en De mortibus persecutorum, indicó que Constancio, padre de Constantino, desaprobaba las medidas persecutorias contra los cristianos de Diocleciano, por lo que se limitó a ordenar la destrucción de sus lugares de culto, sin infligir daño a las personas de los creyentes ${ }^{31}$. Eusebio de Cesarea, en su última edición de la Historia Ecclesiastica, de 324, negó incluso que Constancio dispusiera la demolición de iglesias y oratorios ${ }^{32}$. Sin embargo, en la Vita Constantini, redactada inmediatamente después de la muerte del emperador, en 337, no hizo esta afirmación tan contundente, limitándose a decir que, a diferencia de los otros emperadores, se abstuvo de destruir los lugares de culto ${ }^{33}$. Por añadidura, Eusebio, en esa misma obra, de modo un tanto impreciso, puntualizó que Constancio rechazaba el politeísmo, veneraba a Dios, y que le había consagrado a toda su familia, permitiendo incluso que entraran en su casa sacerdotes para celebrar oficios litúrgi$\cos ^{34}$. Estas afirmaciones podrían pasar por infundadas si no fuera porque el propio Constantino, en un texto oficial trasladado por Eusebio, la llamada «Carta a los provinciales orientales», de 324, había señalado que su padre «había invocado en todas sus acciones a Dios como Salvador», hecho del que se puede colegir que era, al menos, filocristiano ${ }^{35}$.

No obstante, ninguna otra fuente prueba estas noticias aportadas por Eusebio, lo que conduce a pensar que sus aseveraciones son invenciones suyas ${ }^{36}$. Constancio Cloro, en consideración de las fuentes numismáticas y literarias profanas, fue un emperador observante de los cultos tradicionales. Él nunca se identificó como cristiano, sino como un piadoso practicante de los usos religiosos romanos: sus acuñaciones

${ }^{30}$ S. Calderone, «Letteratura ..., pp. 240-249; G. Bonamente, «La "svolta costantiniana"», Chiesa $e$ impero da Augusto a Giustiniano, E. Dal Covolo y R. Uglione, eds., Roma, 2001, pp. 145-170 (=Cristianesimo e istituzioni politiche. Da Augusto a Costantino, Idem, Roma, 1997, pp. 91-116, esp. p. 169); N. Baglivi, «Costantino ..., esp. pp. 230-231; J. F. Shean, Soldiering ..., pp. 265-266.

${ }^{31}$ Lact., De mort. pers., XV, 7.

32 Euseb. Caes., HE, VIII, Ap. 4.

33 Euseb. Caes., $V C$, I, 13.

${ }^{34}$ Euseb. Caes., $V C, \mathrm{I}, 17$.

${ }^{35}$ Euseb. Caes., VC, II, 49 (Traducción de M. Gurruchaga: Eusebio de Cesarea. Vida de Constantino, Madrid, 1993).

${ }^{36}$ En contra de esta opinión, cfr. Th. G. Elliott, «Constantine’s Conversion ..., pp. 421-423. 
representaban a Hércules, Júpiter, Marte y Sol invicto. Ello no impidió que fuera tolerante con los cristianos ${ }^{37}$. Es significativo, a este respecto, que no existan tradiciones martiriales en los territorios sujetos a la autoridad de Constancio durante la persecución de Diocleciano ${ }^{38}$. La explicación más probable de este hecho es que no aplicó las medidas persecutorias más drásticas, aliviando así una presión judicial que consideraba excesiva y políticamente inadecuada. Pero resulta inverosímil que rechazara los cultos tradicionales. En este sentido, Lactancio y, sobre todo, Eusebio, realizaron sendos retratos de Constancio Cloro, destinados a los círculos intelectuales cristianos, y que eran los del padre del primer emperador cristiano ${ }^{39}$. Constantino debía de querer legitimar su propia adhesión personal al cristianismo en 324 manifestando que su padre ya había profesado esa religión. Así, el principado de Constantino quedaba doblemente justificado: tanto en virtud del principio dinástico como del religioso.

Por otra parte, Teodoreto afirmó que Constantino fue convencido por su madre Elena para que se hiciera cristiano, y Gelasio de Cícico, que Constancio y Elena le educaron en el cristianismo ${ }^{40}$. Pero las tradiciones piadosas que recogen estos autores no están refrendadas por ninguna otra fuente. En realidad, Elena, madre de Constantino, no llegó a formar parte de la corte de Constancio, pues había sido repudiada por su marido en el año 293, cuando fue nombrado césar, para casarse con Teodora, hija de Maximiano $^{41}$. Así pues, no fue ella quien introdujo el cristianismo en la casa imperial de Constancio. Además, Eusebio de Cesarea afirma que fue Constantino quien la persuadió para que se hiciera cristiana, se supone que años más tarde, cuando ya era emperador $^{42}$. No resulta, por consiguiente, verosímil la información que ofrecen los historiadores eclesiásticos del siglo V. Además, Constantino fue educado fuera de la corte de su padre. Había permanecido en Nicomedia junto a Diocleciano, al menos desde $297^{43}$. Estaba en el palacio imperial cuando fueron sancionados los cuatro edictos persecutorios de los años 303 y $304^{44}$. Según Eusebio, no los aprobaba, pero tampoco podía oponerse a ellos a causa de su juventud ${ }^{45}$. La excusa carece de fundamento, por-

${ }^{37}$ M. D. Smith, «The Religion of Constantius I», Greek, Roman and Byzantine Studies 38 (1997), pp. 187208, esp. p. 208; C. Buenacasa Pérez, «La “conversión”..., p. 148; K1. M. Girardet, Die konstantinische Wende ..., p. 32. Sobre la piedad de Constancio Cloro, cfr. Pan. Lat., VII (VI), 5, 1: Iustitiam uero patris atque pietatem sequeris (...); Pan. Lat. XII, 4, 4: (...) paterna pietas sequabatur (...); Opt. Porf., VIII, 29: (...) pietate potens Constantius (...). El panegírico VIII, dedicado a Constancio, confirma su particular devoción por Marte, cfr. Pan. Lat. VIII, 15, 3. Sobre las fuentes numismáticas, cfr. M. D. Smith, «The Religion ..., p. 204. Acerca del concepto de pietas en la literatura de la época, cfr. M. J. Rodríguez Gervás, Propaganda política y opinión pública en los panegíricos latinos del bajo Imperio, Salamanca, 1991, p. 79. Sobre su evolución y paulatina asociación a la victoria imperial, cfr. M.-C. L'Huillier, L'Empire des mots. Orateurs gaulois et empereurs romains. 3e. et 4e. siècles, Paris, 1992, pp. 333-336.

${ }^{38}$ Lact., De mort. persec., XVI, 1; Opt. Mileu., I, 22. Cfr. K1. M. Girardet, Die konstantinische Wende ..., p. 31.

39 Véase en este sentido, Cfr. M. D. Smith, «The Religion ..., p. 198.

40 Theodoret., HE, I, 18, 1; Gel. Cyz., III, 6, 1. Cfr. K1. M. Girardet, Die konstantinische Wende ..., p. 28.

${ }^{41}$ Origo, 1; Hieron. Strid., Chron. CCLXVII Olymp. VI.

${ }^{42}$ Euseb. Caes., VC, III, 47, 2. Cfr. J. W. Drijvers, Helena Augusta. The Mother of Constantine the Great and the Legend of Her Finding of the True Cross, Leiden, 1992, p. 35.

${ }^{43}$ Euseb. Caes., VC, I, 19-20.

${ }^{44}$ Or. ad sanct. coet., XXV.

${ }^{45}$ Or. ad sanct. coet., XXV; Euseb. Caes., VC, I, 12. 
que Constantino tenía entonces treinta y dos años ${ }^{46}$. Y si no presenció ejecuciones de cristianos, sí tuvo que tener constancia de ellas. De hecho, Eusebio advierte de que las medidas afectaron, de modo particular, al personal palatino de fe cristiana ${ }^{47}$. En efecto, Pedro, que murió a causa de las torturas que le fueron infligidas, fue procesado en presencia de Diocleciano y Galerio, y, se supone, también de otros miembros destacados de la corte ${ }^{48}$. Tampoco pudieron pasarle desapercibidas las ejecuciones del obispo de Nicomedia, Antimo, y de otros muchos fieles de la ciudad, ordenadas después de que se considerara a los cristianos culpables de haber provocado un incendio en el palacio imperial ${ }^{49}$. Debió de ser por entonces cuando Constantino conoció a Lactancio, rétor africano afincado en Nicomedia. Lactancio, a pesar de ser cristiano, no fue ejecutado por su prestigio intelectual. De todos modos, pasó serias dificultades económicas porque sus alumnos habían abandonado su escuela ${ }^{50}$. Constantino no era entonces cristiano. Acaso había recibido algunas ideas sobre el cristianismo en el seno de su familia, pero debió de hacerse una mejor idea de lo que era durante sus años en Nicomedia. Al margen de que pudiera haber cierto afecto por el cristianismo en su familia, las declaraciones procesales de los cristianos contenían suficientes nociones doctrinales como para conocer los fundamentos de su religión. Y si Constantino estaba disconforme con las medidas persecutorias, es probable que fuera en Nicomedia donde determinara en el futuro su actitud personal hacia los cristianos.

\section{EL PERÍODO DE 306-312}

Cuando Galerio sucedió a Diocleciano, Constantino colaboró como tribuno en sus campañas contra los sármatas en el año 305. Ese mismo año volvió al lado de Constancio ${ }^{51}$. Apenas permaneció un año junto a su padre: le alcanzó en Gesoriacum y le acompañó, junto a sus hermanos y hermanas, hasta el momento de su muerte, cuando se había establecido en Eboracum ${ }^{52}$. Allí fue nombrado emperador, con título de Augusto, por las tropas de su padre. Según Lactancio, inmediatamente después de ser aclamado, Constantino restableció la libertad religiosa con la publicación de la sanctio ${ }^{53}$. El testimonio de Lactancio ofrece muchas dudas. La principal es que, si existió esa sanctio, ¿por qué no incluyó su tenor en De mortibus persecutorum, al igual que hizo con el edicto de Galerio y los acuerdos de Milán? Por otra parte, no se encuentra ninguna referencia a esta primera sanción de Constantino en otras fuentes, cristianas o pro-

\footnotetext{
${ }^{46}$ Según Jerónimo de Estridón, murió con sesenta y seis años, luego había nacido en 271. En 303 tenía, por tanto, treinta y dos. Cfr. Hieron. Strid., Chron., CCLXXVIII Olymp. XXXI.

${ }^{47}$ Euseb. Caes., $H E$, VIII, 6; Euseb. Caes., $V C$, I, 15.

${ }^{48}$ Euseb. Caes., HE, VIII, 6, 2-4.

49 Euseb. Caes., HE, VIII, 6, 6.

${ }^{50}$ Hieron. Strid., De uiris illustr., LXXX.

51 Origo, 2-3.

52 Origo, 6; Euseb. Caes., VC, I, 23.

${ }^{53}$ Lact., De mort. persec., XXIV, 9: Suscepto imperio Constantinus Augustus nihil prius egit quam cristianos cultui ac deo suo reddere. Haec fuit prima eius sanctio sanctae religionis restitutae.
} 
fanas. La afirmación de Lactancio parece, por consiguiente, falsa. El autor, que escribió su libelo contra los perseguidores en 313 o 314, trataba de justificar el compromiso del emperador con los cristianos desde el mismo momento en el que fue proclamado Augusto ${ }^{54}$. Constantino, no obstante, en el contexto posterior a su victoria sobre Majencio, cuando buscaba el apoyo político del clero cristiano, debía de aceptar la versión de los hechos elaborada por Lactancio. En todo caso, Constantino continuó practicando en su jurisdicción la política de no aplicar las medidas persecutorias, que, por otra parte, después de la abdicación de Diocleciano, eran ignoradas. Pero esta política de tolerancia no tuvo definición legal cuando Constantino alcanzó el imperio ${ }^{55}$.

No obstante, el testimonio de Lactancio fue redactado cuando Constantino ya había adquirido compromisos oficiales con el cristianismo. Los textos oficiales de la época, tanto la colección de panegíricos latinos como las leyendas monetarias, representan a Constantino como un emperador observante y protector de los cultos tradicionales. Las expresiones públicas de su religiosidad se acomodaban a las circunstancias de su ejercicio del principado. En su condición de uno de los tetrarcas que habían aceptado los acuerdos de Carnuntum, fue uno de los dedicantes de la inscripción que conmemoraba la restauración de un templo de Sol Invicto Mitra ${ }^{56}$. Además, en consideración de los tipos monetarios, Constantino era oficialmente un defensor de la religión tradicional en su expresión tetrárquica, y, como tal, proclamaba a Júpiter, Hércules y Marte sus protectores (conseruatores) ${ }^{57}$.

Los acuerdos de Carnuntum no fueron respetados. Los mutuos recelos entre los emperadores occidentales llevaron a Constantino a enfrentarse en armas en 310 con su suegro Maximiano, que murió asesinado por un anónimo soldado ${ }^{58}$. Desde este momento, Constantino, que no reconocía a su cuñado Majencio, actuó como único Augusto de Occidente. Este hecho explica su desvinculación de la ideología tetrárquica

\footnotetext{
${ }^{54}$ Considerando que el Bellum Cibalense tuviera lugar en el año 314, tal y como indica Jerónimo de Estridón (Hieron. Strid., Chron., CCLXXIII Olymp. VIII). Sobre la fecha de redacción de De mortibus persecutorum. Cfr. J. R. Palanque, «Sur la date du De mortibus persecutorum», Mélanges d'archéologie, d'épigraphie et d'histoire offerts à Jérôme Carcopino, Paris, 1966, pp. 711-716; T. D. Barnes, «Lactantius and Constantine», Journal of Roman Studies 63 (1973), pp. 29-46, esp. pp. 31-32, 39-46; R. Teja Casuso, Lactancio. Sobre la muerte de los perseguidores. Introducción, traducción y notas, Madrid, 1982, pp. 16-20.

55 A. Lippold, "Konstantin und die Christen bis 312 n Chr.», Staat, Kultur, Politik. Beiträge zur Geschichte Bayerns und des Katholizismus. Festschrift zum 65. Geburtstag von Dieter Albrecht, W. Becker y W. Chrobad, eds., Kallmünz, 1992, pp. 1-9, esp. p. 3; K1. Rosen, «Constantins Wed zum Christentum und die Panegyrici Latini», Costantino ..., II, Macerata, 1993, pp. 853-863, esp. p. 855; K1. M. Girardet, Die konstantinische Wende ..., p. 56. En contra, cfr. Th. G. Elliott, «Constantine’s Conversion ..., p. 424; P. A. Barceló, «Die Religionspolitik Kaiser Constantins vor der Schlacht von 312», Hermes 116 (1988), pp. 76-94.

${ }^{56}$ CIL III, 441 (Dessau 659). Los Panegyrici Latini de época tetrárquica proporcionan ejemplos muy ilustrativos de los predicados religiosos promovidos desde instancias oficiales, cfr. Pan. Lat. X, 6; XI, 3, 6-8; VIII, 4, 1; IX, 10. Cfr. C. Castello, «Il pensiero politico-religioso di Costantino alla luce dei panegirici», Accademia Romanistica Costantiniana, I, Perugia, 1975, pp. 49-117, esp. pp. 67-69.

${ }^{57}$ Hércules: RIC, Rom. 139-R5; Ti. 90-R4; RIC, 298-R2, 299 y 300-R; Marte: RIC, 884-C2; Ti. 124 y 126 S/R; Lug. 263-R; Lon. 95-R; 725-C2; Tr. 772a-C; Lon. 108-S; Tr. 775-S; Tr. 732-R2; Tr. 779-R; Júpiter: RIC, Sis. $180 \mathrm{~b}-\mathrm{R}$.

${ }^{58}$ Pan. Lat. VI (VII), 20, 1. Lact., De mort. persec., XXIX, 7-8; Aurel. Vict., XL, 22; Eutrop. X, 3, 2; Hieron. Strid., Chron. CCLXXI Olymp., An. XXX, II.
} 
a partir de esa fecha, y la adopción de un discurso religioso oficial orientado a la legitimación de un principado monárquico, que evocaba la figura de Augusto. Ejemplo de ello es el panegírico latino de 310, que narra la llamada «visión pagana» de Constantino ${ }^{59}$. Según el anónimo discurso, al poco de derrotar a Maximiano y de saber que había sido contenido un nuevo ataque de los francos en la frontera renana, el emperador se dirigió a cumplir un voto por su victoria en un templo de Apolo, que a todas luces era el complejo cultual de Grand ${ }^{60}$. Allí, el rétor anónimo afirma que Constantino había visto a Apolo acompañado por la Victoria, quienes le ofrecían unas coronas de laurel presagiándole treinta años, y que el príncipe se había reconocido en los rasgos del dios ${ }^{61}$. Constantino se hizo representar en este discurso no sólo como un piadoso cumplidor de votos hacia Apolo, sino como merecedor de una visión de una divinidad, lo que le convertía también en un intermediario entre lo divino y lo huma$\mathrm{no}^{62}$. Era una forma de legitimar su ejercicio del principado ante unas tropas entonces formadas mayoritariamente por observantes de los cultos tradicionales. Además, el emperador quería identificarse con sus súbditos, los provinciales galos, entre quienes estaba muy difundida la devoción a la divinidad local de Grand ${ }^{63}$.

\section{LA GUERRA CONTRA MAJENCIO Y LA DIARQUÍA (312-324)}

Derrotado Maximiano, Majencio era el único competidor que Constantino tenía para hacerse dueño de todas las provincias occidentales. Constantino controlaba Galia, pero Majencio era fuerte en Italia. Constantino fue reconocido en Turín después de una batalla, pero fue bien recibido en Milán ${ }^{64}$. La caída de Verona en manos de Constantino precipitó la derrota de Majencio a las puertas de Roma ${ }^{65}$. Todo esto ocurría en contra de lo indicado por los presagios formulados por los harúspices que le acompañaban ${ }^{66}$. En esta ocasión, los ritos tradicionales no habían servido a los em-

${ }^{59}$ Sobre la misma, cfr.: B. Saylor Rodgers, «Constantine's Pagan Vision», Byzantion, 50 (1980), pp. 259278; M.-C. L'Huillier, L'Empire ..., pp. 377-384; Mª V. Escribano Paño, «La primera visión de Constantino (310)», Sueños, ensueños y visiones en la Antigüedad pagana y cristiana, R. Teja Casuso, ed., Gijón, 2002, pp. 85-94. Castello, sin embargo, observa que el capítulo que relata la visión desarrollaba la propia ideología tetrárquica. Cfr. C. Castello, «Il pensiero ..., pp. 80-81.

${ }^{60}$ Pan. Lat. VII (6), XXI, 2-3. Sobre estos sucesos, cfr. C. E. V. Nixon y B. Saylor Rodgers, In Praise of Late Roman Emperors. The Panegyrici Latini. Introduction, Translation and Historical Commentary with the Latin Text of R. A. B. Mynors, Berkeley, 1994, pp. 246-247, nn. 87-86.

${ }^{61}$ Pan. Lat. VII (6), XXI, 4-5.

${ }^{62}$ M.-C. L'Huillier, L'Empire ..., pp. 377-384.

${ }^{63}$ C. Castello, «Il pensiero ..., pp. 80-81; M. J. Rodríguez Gervás, Propaganda ..., pp. 133-135.

${ }^{64}$ Pan. Lat., XII, 6-7.

65 Origo, XII.

${ }^{66}$ Pan. Lat. XII, 2, 4: (...) contra haruspicum monita (...). Cfr. S. Montero Herrero, Politica y adivinación en el Bajo Imperio Romano: emperadores y harúspices (193 D. C.-408 D. C.), Bruxelles, 1991, pp. 63-64; J.L. Desnier, «Quelques remarques sur l'Etrusca disciplina dans les panégyriques latins», Des Sévères à Constantin: les écrivains latins du IIIe. siècle et l'Etrusca disciplina: actes de la table ronde, ENS 24 et 25 octobre 1997, Tours, 2000, pp. 63-70; I. Ramelli, Cultura e religione etrusca nel mondo romano. La cultura etrusca dalla fine dell'independenza, Alessandria, 2003, pp. 137-138. 
peños políticos y estratégicos de Constantino, pues habían resultado serle adversos y, además, fallidos. Ante esta situación, Constantino emprendió la búsqueda de nuevas formas religiosas que refrendaran sus aspiraciones de hacerse, al menos, con la autoridad sobre las provincias occidentales. Para ello no dudó en proclamar que había vencido gracias a la intervención de un dios desconocido e incognoscible, con el que tenía una relación personal y exclusiva (quem enim te ipse dici uelis, scire non possumus) ${ }^{67}$. Así, el panegirista del año 313 le pregunta: Quisnam te deus, quae tam praesens hortata maiestas ut, (...) contra haruspicum monita, ipse per temet liberandae Vrbis tempus uenisse sentires? ${ }^{68}$. Esta divinidad estaba caracterizada por el henoteísmo y el sincretismo. Además, sólo se había revelado a Constantino (uni se tibi dignatur ostendere). Era una divinidad henoteísta porque había encomendado a otros dioses (llamados inferiores) el cuidado de todos los ciudadanos del Imperio, con la excepción del propio emperador (delegata nostri diis minoribus cura) ${ }^{69}$. Era una divinidad sincrética, puesto que tenía tantos nombres como lenguas había querido que hubiera (cuius tot nomina sunt quot gentium linguas esse uoluisti) ${ }^{70}$. Era un dios creador y gobernador providente del mundo (mundi creator et dominus), superior a cualquier otro poder sobrenatural (summe rerum sator), pero, sobre todo, era un protector de la persona de Constantino y de sus tropas ${ }^{71}$. No se trataba de Cristo, sino de una divinidad de corte tradicional, distinta de Júpiter, Apolo o de cualquiera de los dioses de los romanos. El nuevo e incógnito dios fue reconocido por el Senado, en cuyo honor dedicó un signum dei $i^{72}$. Debía de tratarse de una estatua o de un estandarte con una figuración de la divinidad. Es posible que se tratara este signo de una estrella de ocho puntas, representada frecuentemente en monedas constantinianas exenta en campo o inscrita en un globo alzado sobre un altar $^{73}$.

El error de los harúspices debió de demostrar la escasa fiabilidad y utilidad política circunstanciales de la religión tradicional. Aunque fuera el cultus deorum la religión pública del Imperio, tampoco era la única que existía. El cristianismo lo conocía ya de sus círculos familiares y de la importante comunidad formada en Nicomedia. Galerio, viendo la escasa eficacia de las medidas persecutorias de Diocleciano, había concedido en 311 la amnistía (indulgentia) a los cristianos, en un acto de clemencia, atendiendo al interés público, siempre que no contravinieran la moral tradi-

${ }^{67}$ Pan. Lat. XII, 26, 1. Sobre la divinidad ignota, cfr. C. Buenacasa Pérez, «La “conversión” ..., p. 159.

${ }^{68}$ Pan. Lat. XII, 2, 4.

${ }^{69}$ Pan. Lat. XII, 2, 5.

${ }^{70}$ Pan. Lat. XII, 26, 1.

${ }^{71}$ Pan. Lat. XII, 13, 2.

72 Pan. Lat. XII, 25, 4

${ }^{73}$ RIC VII, The. 48, 50 (318-319); Lon. 199, 224; Lug. 198, 247, 275; Tr. 303; 304, 369 (Globo, años 321 323); Ant. 84; Ale. 41, 50 (Exenta en campo, 313-314); Cons. 8; Are. 269; Ale. 35; Lon. 295; Nic. 31, 122 (Exenta en campo, 324-325). Acerca de esta representación, cfr. J. I. San Vicente, Moneda y propaganda política: de Diocleciano a Constantino, Vitoria, 2002, p. 162; F. López Sánchez, Victoria Augusti. La representación del poder del emperador en los reversos monetales romanos de bronce del siglo IV d. C., Zaragoza, 2004, p. 87. La estrella de ocho puntas no es un emblema exclusivo de las acuñaciones de Constantino. Aparece ya en las de Diocleciano (RIC VII, Tr. 266), Constancio Cloro (Tr. 329) o Galerio (Lug. 165, 166). 
cional romana y que rogaran por la salud del emperador y la del Imperio ${ }^{74}$. Pocos meses después, Constantino se reunió con Licinio en Milán para pactar el reparto de los territorios romanos. El acuerdo se selló con el matrimonio entre Constancia, hermana de Constantino, y Licinio ${ }^{75}$. Pero, además, Constantino quería proteger a los cristianos por afinidad hacia su religión y Licinio estaba interesado en favorecerles más de lo que había hecho Galerio. Licinio tenía sus particulares razones para aplicar el tratado: su corte se iba a establecer en Nicomedia y estaba interesado en tener buenas relaciones tanto con el personal palatino, cuyos miembros cristianos habían sufrido las medidas de Diocleciano, como con la población de la ciudad, donde había muchos afectados por las leyes persecutorias. Les convenía a ambos Augustos concederles la plena libertad religiosa. En efecto, el texto de los acuerdos especificaba que se habían reunido para tratar todas las cuestiones que concernieran al bienestar y a la seguridad pública (uniuersa quae ad commoda et securitatem publicam pertinerent). El resultado de las negociaciones fueron los acuerdos o tratado de Milán (tractatus, señala el texto, que no tuvo forma de edicto, sino de carta imperial), que concedía a todos los ciudadanos del Imperio, incluyendo a los cristianos, la libera potestas sequendi religionem, además de asegurar que ninguna religión sería restringida. Por añadidura, los Augustos habían acordado devolver tanto a las comunidades cristianas como a sus fieles las propiedades que les hubieran sido confiscadas. Las Litterae Licinii no contienen ninguna declaración de fe: más bien se expresan en términos neutrales con relación a los seres sobrenaturales, a fin de que les sean propicios quienesquiera que fueran (quicquid est diuinitas in sede caelesti, ...ut possit nobis summa diuinitas, ... in omnibus solitum fauorem suum beniuolentiamque praestare $)^{76}$. Lactancio confirma que fueron dirigidos en forma de carta por Licinio al gobernador de Bitinia, para su publicación en Nicomedia el 13 de junio de 313 , mes y medio después de derrotar a Maximino Daza ${ }^{77}$. Pero debieron de circular por todo el Imperio, como demuestra su inclusión en De mortibus persecutorum de Lactancio.

Los cristianos eran una comunidad religiosa minoritaria, pero numerosa e influyente, por su jerarquía y disciplina ${ }^{78}$. A Constantino se lo demostró la querella donatista: una parte de los cristianos africanos se había escindido de la Iglesia. Era un grupo de fieles rigoristas que no reconocían la validez de la ordenación episcopal de Ceciliano de Cartago, por haber intervenido en la misma el traditor Félix de Abthungi. A consecuencia del cisma, en la práctica, en África había dos iglesias distintas, la católica y la donatista. Puesto que un concilio celebrado en Cartago no le había dado la razón, Ceciliano recurrió a la ayuda del procónsul Anulino, quien, a su vez, expu-

\footnotetext{
${ }^{74}$ Lact., De mort. persec., XXXIV; Euseb. Caes., HE, VIII, 17, 3-10. Cfr. P. Siniscalco, «L'editto di Galerio del 311. Qualche osservazione storica alla luce della terminologia», Accademia Romanistica Costantiniana, X, Perugia, 1995, pp. 41-53.

${ }^{75}$ Lact., De mort. persec., XLV, 1.

${ }^{76}$ Lact., De mort. persec., XLVIII, 2-12; Euseb. Caes., HE, X, 5, 2-3.

77 Lact., De mort. persec., XLVIII, 1.

${ }^{78}$ P. Veyne, Quand ..., pp. 52-54.
} 
so el problema al emperador, y, éste, al obispo de Roma, Milcíades ${ }^{79}$. Como las disposiciones imperiales no convencieron a la parte donatista, Constantino convocó un Concilio en Arelate en 314, para que solventara la crisis eclesiástica ${ }^{80}$.

El emperador sabía que debía tener buenas relaciones con los cristianos. Así, a propósito del comienzo de la querella donatista, devolvió a la Iglesia todas las propiedades que le hubieran sido embargadas a finales de $312^{81}$. Un año después, en 313 , concedió a los clérigos católicos la exención de munera publica ${ }^{82}$. Al margen de que Constantino fuera afecto al cristianismo, había razones de corte pragmático que justificaban estas medidas: la Iglesia custodiaba el culto de «la majestad divina suprema», luego procuraba al Imperio la prosperidad y la felicidad generales ${ }^{83}$. Es en este contexto cuando Constantino comenzó a identificarse como cristiano, en su condición de príncipe que gozaba de la protección divina. En la carta que envió al nuevo procónsul de África, Elafio, decía: (...) summa dininitas (...) curae nutu suo caelesti terrena omnia moderanda commisit $(. . .)^{84}$. Esta manifestación visual cristiana no es el anuncio de la victoria de Puente Milvio. Según este pasaje, la «divinidad suprema» (en clara referencia al Dios de los cristianos) le había encomendado el gobierno de todas las cosas terrenas con su señal celeste. A partir de este momento, Constantino se consideró cristiano, aunque este hecho no se tradujera de modo ritual. Lo confirma la carta que dirigió Constantino a los obispos reunidos en el Concilio de Arelate:

La eterna y religiosa piedad de nuestro Dios no permite de ningún modo que la condición humana camine por más tiempo errante en tinieblas, ni que padezca que prevalezcan por más tiempo las voluntades aborrecibles, para que no de nuevo, manifestando su camino de salvación, les dé con sus muy diáfanos resplandores la vuelta a la regla de la justicia. Pues tengo constancia de ello gracias a muchos ejemplos, entre los cuales, cuento el mío propio. Había en mí antes cosas que parecian carecer de justicia, y en nada podía ver el supremo poder que actuaba dentro de lo más profundo de mi pecho. (...) Pero Dios omnipotente, que habita en las alturas del cielo, me procuró lo que no merecía: ciertamente, no se puede ni decir ni enumerar (todo) lo que me ha concedido la la benevolencia divina ${ }^{85}$.

${ }^{79}$ Euseb. Caes., $H E, 10,5,18-20$.

${ }^{80}$ Opt. Mileu., App. III. Cfr. K1. M. Girardet, Die konstantinische Wende ..., pp. 136-138.

${ }^{81}$ Euseb. Caes., $H E, 10,15-17$.

${ }^{82}$ Euseb. Caes., $H E, 10,7$.

${ }^{83}$ Euseb. Caes., $H E, 10,7$.

${ }^{84}$ Opt. Mileu., App. III.

${ }^{85}$ Opt. Mileu., App. V: Aeterna et religiosa pietas Dei nostri nequaquam permittit humanam condicionem diutius in tenebris oberrare neque patitur exosas quorundam uoluntates usque in tantum perualere, ut non suis praeclarissimis luminibus denuo pandens iter salutare eas det ad regulam iustitiae conuerti. Habeo quippe cognitum multis exemplis, haec eadem ex me ipso metior. Fuerunt enim in me primitus, quae iustitia carere uidebantur, nec ulla putabam uidere supernam potentiam quae intra secreta pectoris mei gererem. (...). Sed Deus omnipotens in caeli specula residens tribuit, quod non merebar: certe iam neque dici neque enumerari possunt ea, quae caelesti in me beniuolentia concessit. 
Aunque el autor jurídico de la carta sea Constantino, la forma y el contenido parecen corresponder a Lactancio ${ }^{86}$. El texto describe un camino de búsqueda intelectual de la verdad similar al descrito por el rétor en De ira Dei. El emperador quería presentarse de este modo como un intelectual que reconocía el cristianismo como «camino de salvación», y a Dios como un benefactor de la humanidad que ofrecía la conversión a su «regla de justicia» (det ... ad regulam iustitiae conuerti $)^{87}$. Aunque no se hace referencia alguna a ritos de paso (como pudiera ser el catecumenado), Constantino afirmaba que el hecho de la conversión a la «regla de justicia» se había verificado en él y en otras personas (Habeo quippe cognitum multis exemplis, haec eadem ex me ipso metior), $\mathrm{y}$, en consecuencia, se define como su siervo (me famulum suum). Más allá de la expresión de servilismo hacia la divinidad revelada, el emperador se equipara a los obispos en calidad de su consiervo ${ }^{88}$. Algunos años más adelante, después del sínodo niceno, el desarrollo de este predicado dará lugar a que Constantino presente como «obispo de los de fuera» (episkopos tôn ektós). Esta fórmula encubría una posición de supremacía jerárquica del emperador en relación con el episcopado, puesto que el príncipe asumía la responsabilidad de hacer cumplir a todos los ciudadanos, cristianos o no, la doctrina cristiana ${ }^{89}$.

Como se ha podido observar, el reconocimiento de Constantino de la revelación cristiana no se produjo, según este documento oficial, después de un acontecimiento sobrenatural: fueron los beneficios que Dios le había concedido lo que le había llevado a esta convicción, tantos que no podía ni referirlos ni enumerarlos (certe iam neque dici neque enumerari possunt ea, quae caelesti in me beniuolentia concessit). Pero no se trata este testimonio de un documento aislado. Si Constantino se había declarado cristiano a su modo, también fue aceptado como tal, al menos, por los autores cristianos. Un texto anónimo en verso, las Laudes Domini, redactado entre 317 y 321 , fue dedicado al emperador señalando que era un «maestro» por su regla de vida y otro tanto por sus leyes, sancionadas por la norma que se le había establecido (quae lex tibi condita sancit $)^{90}$. También el carmen VIII de Optaciano Porfirio, compuesto entre 320 y 321 , señala que el pueblo romano obedecía las normas por temor a Constantino y a la fe, «bajo la ley probada de Cristo ${ }^{91}$.

\footnotetext{
${ }^{86}$ E. d. P. Digeser, «Lactantius and Constantine's Letter to Arles: Dating the Divine Institutes», Journal of Early Christian Studies 2 (1994), pp. 33-52.

${ }^{87}$ Concepto de iustitia que sería equivalente a ueritas. Cfr. T. G. Elliott, «Constantine’s ..., pp. 430-431.

${ }^{88}$ R. Van Dam, «The Many Conversions ..., pp. 138-141.

${ }^{89}$ Euseb. Caes., VC, IV, 24. Sobre esta interpretación, cfr. E. Moreno Resano, «El elogio del emperador Constantino en la literatura cristiana de su época», Anuario de Historia de la Iglesia 22 (2013), pp. 83-109, esp. pp. 106-107.

${ }_{90}$ Laud. Dom., 143-147: At nunc tu dominum meritis, pietate parentem / imperio facilem, uiuendi lege magistrum / edictisque parem, quae lex tibi condita sancit, / uictorem laetumque pares mihi Constantinum! (...). Sobre la obra, cfr. A. Salzano, Laudes Domini. Introduzione, testo, traduzione e commento, Napoli, 2001, pp. 13-16; R. Gees, «The Rhetoric and Poetics of Praise in the Laudes Domini», Quaderni Urbanitati di Cultura Classica 95 (2010), pp. 71-84.

${ }^{91}$ Opt. Porf., Carmen VIII, 3-5 Summe, faue. Te tota rogat plebs gaudia rite, / et meritam credit, cum seruat iussa timore / Augusto et fidei, Christi sub lege probata.
} 
Lactancio aprovechó la ocasión de que Constantino hubiera profesado su nueva fe para elaborar una versión cristiana de la derrota de Majencio a las puertas de Roma en De mortibus persecutorum. La obra en cuestión, dirigida al confesor Donato, señalaba que el emperador había recibido una admonición sobrenatural mientras dormía que le conminaba a dibujar sobre los escudos de sus soldados un signum Dei. Este símbolo era el anagrama formado por la letra griega X girada sobre sí con la parte superior de uno de sus brazos curvado (de lo que resulta el nexo de las dos primeras letras de Cristo en griego) para vencer a su adversario en batalla ${ }^{92}$. Conviene precisar que Lactancio no describe exactamente una visión, sino una admonición durante el sueño. Eusebio recogió el mismo episodio con algunas diferencias en la Vita Constantini, pues, según su relato, el emperador produjo la visión de la Cruz durante el día, seguida de una admonición en sueños durante la noche ${ }^{93}$. De todos modos, la principal diferencia entre las dos versiones es que Lactancio refirió la revelación como una revelación del Dios único del cristianismo como divinidad tutelar de Constantino y Eusebio la presentó como una confirmación del favor divino hacia el emperador ${ }^{94}$. Lactancio se inspiró en la literatura veterotestamentaria para construir la visión de Constantino, en concreto, la aparición del profeta Jeremías a Judas Macabeo anunciándole la victoria contra los enemigos de Israel ${ }^{95}$. El emperador asumió el crismón como emblema de la singular protección que le ofrecía Cristo. En la primera representación documentada, del año 315, este emblema tenía una interpretación subordinacionista, acorde con la cristología lactanciana ${ }^{96}$. Después del Concilio de Nicea, el crismón pasará a ser glosado en clave trinitaria ${ }^{97}$. De todos modos, en De mortibus persecutorum, el beneplácito de Dios hacia las acciones de los emperadores no dependía de que hubieran abrazado el cristianismo, sino de que protegieran a los cristianos. De hecho, según Lactancio, también Licinio, entonces filocristiano, recibió la aparición de un ángel antes de enfrentarse en batalla con Maximino Daza ${ }^{98}$.

No obstante, ni la declaración de fe realizada a los obispos reunidos en Arelate ni el pasaje de la visión del monograma de Cristo realizado por Lactancio comprometieron a Constantino ni en exceso ni en exclusiva con el cristianismo. El arco que el Senado dedicó a Constantino en 315 recordaba que el emperador había vencido instinctu diuinitatis, en alusión al dios incógnito al que hace referencia el panegírico de $313^{99}$.

92 Lact., De mort. persec., XLIV, 5.

93 Euseb. Caes., VC, I, 28-29.

94 T. G. Elliott, «Constantine's Conversion ..., p. 428.

952 Mac., 15, 12-17. Cfr. J. Amat, Songes et visions. L'au-delà dans la littérature latine tardive, Paris, 1985 , pp. 204-205, n. 48.

${ }^{96}$ In / signo hoc est Patris uictoria. Imp. Lic. Licini. Nos. IV Cos. Cfr. V. Santa Maria Scrinari, Il Laterano imperiale, 1: Dalle «aedes Laterani» alla «domus Faustae», Città del Vaticano, 1991, pp. 163-164, 172; J. Bardill, Constantine ..., p. 164. Sobre la cristología de Lactancio, cfr. P. Mc. Guckin, «The Christology of Lactantius», Studia Patristica XVII (1982), pp. 813-820.

${ }^{97}$ Opt. Porf., Carmen XXIV, Versus intexti: Omnipotens Genitor tuque o diuisio mixta, / Filius atque Pater et Sanctus Spiritus unum, / faueas uotis.

${ }^{98}$ Lact., De mort. persec., XLVI, 3-4.

99 CIL VI, 1139. 
En este monumento aparecía el emperador sacrificando a Diana y a Silvano y ofreciendo los suouetaurilia para purificar a sus tropas ${ }^{100}$. Del mismo modo, Optaciano Porfirio, dentro de la colección de caligramas que dedicó al emperador en 326, se encuentra uno que figura un altar dedicado a Apolo Pitio ${ }^{101}$. La composición no hace referencia directa a Constantino. Posiblemente ni siquiera fue redactado en esa fecha para honrarle, sino algunos años antes y como divertimento literario, pero el conjunto de la obra le agradó al emperador, pues correspondió la dedicatoria del autor con las palabras «Gratum igitur hoc mihi dicationis tuae munus fuit» ${ }^{102}$. Era la representación visible de que el emperador seguió observando los cultos tradicionales hasta el año 315. Nada indica que dejara de hacerlo antes de 324.

No obstante, a Constantino también le complació su representación como príncipe filocristiano que había elaborado Lactancio, puesto que en ella aparecía como emperador victorioso por beneplácito de una divinidad. Toda la propaganda le podía resultar útil políticamente. Esta actitud hacia el cristianismo no sólo la mostró Constantino. En el sermón que pronunció Eusebio de Cesarea durante la consagración de la basílica de Tiro (quizá en 314), tanto Constantino como Licinio «conscientes del honor que habian obtenido, escupían al rostro de los idolos muertos, pisoteaban las criminales ceremonias de los demonios y se burlaban del antiguo engaño transmitidos por sus mayores; y, en cambio, reconocían que hay un solo Dios, único y él mismo, bienhechor común de todos y de ellos mismos, y confesaban a Cristo como Hijo de Dios (...), en estelas le proclamaban Salvador (...)» ${ }^{103}$. De nuevo, las afirmaciones de Eusebio resultan inverosímiles: ni Constantino ni Licinio habían renunciado a los ritos consuetudinarios, y sólo Constantino había hecho manifestaciones de adhesión al cristianismo. Pero Licinio entonces era todavía filocristiano.

Las cosas cambiaron cuando las relaciones con su cuñado se rompieron después del asunto de Basiano y del episodio del derribo de las estatuas de Constantino en Emona, que llevaron a ambos Augustos a enfrentarse en armas en 314 y 316 , y de nuevo, entre 323 y $324^{104}$. El período que medió entre las guerras civiles de los Augustos dio lugar a nuevas concepciones religiosas. Licinio se desentendió del cristianismo, para promover los cultos sincréticos de tradición helenística en las provincias orientales. Entretanto, Constantino actuó en Occidente como defensor de la tradición religiosa romana, prohibiendo algunas prácticas de los harúspices (cuyos servicios tan

\footnotetext{
100 J. Bardill, Constantine ..., pp. 236 (Diana y Silvano), 238 (suouetaurilia) (figs. 155, 156 y 159).

101 Opt. Porf., Carm., XXVI.

102 Opt. Porf., Ep. Constantini.

${ }^{103}$ Euseb. Caes., HE, X, 4, 16. Traducción de A. Velasco Delgado, Eusebio de Cesarea. Historia eclesiástica. Versión española, introducción y notas de, Madrid, 2001, pp. 603-604.

${ }^{104}$ Basiano era esposo de Anastasia, hermana de Constantino. Éste propuso a Licinio que Basiano gobernara Italia en calidad de césar. Pero Licinio lo impidió, levantando a Basiano en armas contra Constantino por medio de su hermano Senición. Ambos hermanos fueron ejecutados. Licinio acabó ordenando el derribo de las estatuas de Constantino en Emona. En 314 se enfrentaron en armas en el Campus Cibalensis y dos años después en Campus Ergenus. Aunque se restableció la paz entre los Augustos, Constantino invadió las provincias de Licinio en 323 y le derrotó un año después en Crisópolis. Cfr. Origo, XIV-XVIII; Hieron. Strid., Chron., CCLXXIII Olymp. VII.
} 
poco útiles le habían sido en la guerra contra Majencio), e instituyendo fiestas tradicionales como el día del Sol ${ }^{105}$. Licinio se alejó completamente del cristianismo, en tanto que Constantino daba un tratamiento privilegiado a la Iglesia. La desafección de Licinio por el cristianismo obedece a distintas razones. Por una parte, los cristianos orientales, atendiendo a los favores prestados por Constantino a las comunidades occidentales, eran decididamente partidarios suyos ${ }^{106}$. Este hecho empeoró aún más su situación ante el emperador. Licinio expulsó a los cristianos de palacio ${ }^{107}$. Por otra parte, el inicio de la querella arriana ofreció a Licinio una imagen muy mala de la Iglesia, sobre todo, después de que el Concilio de Alejandría del año 320 no consiguiera solucionar la controversia doctrinal ${ }^{108}$. En consecuencia, además de limitar las posibilidades de catequizar a las mujeres, les prohibió el intercambio de correspondencia entre obispos, el traslado de obispos fuera de su provincia y la celebración de conci$\operatorname{lios}^{109}$. Las medidas trataban de impedir tanto el proselitismo como la celebración de concilios. Aunque su esposa Constancia era cristiana, su impresión de que los eclesiásticos eran un colectivo conflictivo y desleal que no traía ningún bien al Imperio le llevó a promover una política de hostigamiento ${ }^{110}$. Esta política agresiva, más que persecutoria, llegó a costar la vida al obispo Basilio de Amasea Póntica ${ }^{111}$. De todos modos, la mayor parte de las penas impuestas a los cristianos se limitaron a la privación de bienes, tanto de la Iglesia como de los fieles, y, en el caso de los militares, a la expulsión del ejército ${ }^{112}$.

\footnotetext{
${ }^{105}$ CTh. IX, 16, 1; CTh. IX, 16, 2 (319); CTh. XVI, 10, 1 (320) (haruspicina); CTh. II, 8, 1; CI. III, 12, 2 (321) (Dies Solis). Sobre estas leyes y su contexto, cfr. I. Ramelli, Cultura ..., pp. 140-143; E. Moreno Resano, «La política religiosa y la legislación sobre los cultos tradicionales del emperador Licinio (306324)», Polis 20 (2009), pp. 167-207; Idem, «La ley constantiniana del Dies Solis en su contexto político y legislativo», Studia Historia. Historia Antigua 27 (2009), pp. 187-206; Idem, «El dies Solis en la legislación constantiniana», Antiquité Tardive 17 (2009), pp. 289-305; M ${ }^{\mathrm{a}}$ V. Escribano Paño, «Constantino y Licinio: las leyes constantinianas a propósito de los haruspices (319-320)», Revue Internationale des Droits de l'Antiquité 57 (2010), 197-216.

106 S. Corcoran, «Hidden from History: the Legislation of Licinius», The Theodosian Code, J. Harries y I. Wood, eds., Ithaca, 1993, pp. 97-119, esp. pp. 97-102; S. Corcoran, The Empire of the Tetrarchs: Imperial Pronouncements and Government, AD 284-324, Oxford, 2000, p. 195; T. D. Barnes, Constantine: Dinasty, Religion and Power in the Later Roman Empire, Chichester, 2011, pp. 105-106; J. Bardill, Constantine..., p. 281.

${ }^{107}$ Hieron. Strid., Chron., CCLXXV Olymp.

108 Athan. Alex., De syn., XVI; Socr. Const., HE, I, 6, 4; Soz., HE, 1, 15; Theod. Cyr., HE, I, 3. Cfr. M. Edwards, «Synods and Councils», Cambridge History of Christianity, A. Casiday y F. W. Norris, eds., II, Cambridge, 2007, pp. 367-402, esp. p. 369.

${ }^{109}$ Euseb. Caes., VC, I, 51, 1-3. Cfr. S. Calderone, Costantino e il Cattolicesimo, I, Firenze, 1962, pp. 217230; X. Leviels, Contra Christianos. La critique sociale et religieuse du christianisme des origines au Concile de Nicée (45-325), Berlin, 2007, pp. 480-487, esp. pp. 487 y 302.

${ }^{110}$ Es célebre la carta que le dirigió Eusebio de Cesarea cuando era Augusta de Oriente a propósito de la veneración de las imágenes (cfr. H. Hennekopf, Textus Byzantini ad iconomachiam pertinentes, Leiden, 1969, pp. 42-44). Sobre la afiliación religiosa de Constancia, cfr. H. A. Pohlsander, "Constantia», Ancient Society 29 (1993), pp. 151-167, esp. pp. 157-158. Acerca del carácter de la política anticristiana de Licinio, cfr. Sulp. Seu., Hist. Sacr., I, 33.

111 Hieron. Strid., Chron. CCLXV Olymp. XIIII.

112 Euseb. Caes., VC, II, 33; Sozom., HE, I, 9. Cfr. J. Fernández Ubiña, Cristianos ..., p. 481.
} 


\section{LA MONARQUÍA CONSTANTINIANA (324-337)}

Constantino, sabedor de que había contado con el apoyo de los cristianos en la contienda civil de 323-324, nada más hacerse con el control de las provincias orientales, tuvo con ellos un gesto inusitado de favor: manifestó oficialmente su adhesión exclusiva al cristianismo. No le faltaban razones: Licinio se encontraba confinado en Tesalónica, después de que Constantino aceptara su rendición por mediación de Constancia. Un año más tarde ordenó su ejecución, probablemente, a causa de un intento de sublevación militar ${ }^{113}$. Este hecho -por lo demás, oscurecido gracias a la damnatio memoriae de su cuñado-, advierte de que el dominio logrado por Constantino sobre Oriente era un tanto inseguro. Lo volvió a demostrar un hecho que se suele tener como anecdótico, pero que resulta bastante revelador: en 334 las tropas imperiales tuvieron que hacer frente a la usurpación de un individuo de origen humilde, Calocero $^{114}$. Es decir: además de las armas, Constantino, en 324, se encontraba en la necesidad de buscar el apoyo de ciertos sectores ciudadanos en previsión de un nuevo conflicto. Y los cristianos, bien cohesionados por la disciplina eclesiástica, al margen de las diferencias doctrinales internas, se lo ofrecían.

La primera manifestación pública y para conocimiento general de la fe cristiana de Constantino aparece en un documento del año 324, cuya traducción griega recogió Eusebio en la Vita Constantini, bajo el título de «Carta a los provinciales de Palestina». Sus destinatarios, en realidad, eran todos los ciudadanos de las provincias orientales, como advierte su cláusula de aplicación ${ }^{115}$. A diferencia de la carta dirigida a los obispos reunidos en Arelate en 314, este escrito oficial estaba dirigido no sólo al clero, sino a todos los ciudadanos, cristianos o no. La epístola en cuestión, además de restituir las propiedades perdidas a los cristianos que se hubieran visto afectados por las requisas llevadas a cabo en época de Licinio, proclamaba la distinta disposición de Constantino hacia ellos. Por lo pronto, profesaba su misma fe: «He llegado a la inquebrantable convicción de que debo al sumo Dios toda mi alma, todo lo que respiro y, en suma, todo lo que se revuelve en lo más íntimo del pensamiento» ${ }^{116}$.

No mucho después, en el mismo año 324, volvió a reconocer que compartía las creencias de los cristianos en dos ocasiones: en la carta al rey persa Sapor y en la carta a los ciudadanos orientales ${ }^{117}$. En la misiva dirigida a Sapor, Constantino declaraba: «Guiado por la luz verdadera, reconozco la fe divina. (...) Ya conozco la verdadera religión. Admito sin paliativos que tengo este culto como maestro en el reconocimiento del Dios santísimo» ${ }^{118}$. Constantino no dudaba en reconocer las razones por las que

\footnotetext{
113 Origo, 29; Socr. Const., HE, I, 4.

114 Aurel. Vict., XLI, 11; Hieron. Strid., Chron., CCLXXVIII Olymp. XXVIII.

115 Euseb. Caes., VC, II, 42.

116 Euseb. Caes., VC, II, 29, 1 (Traducción de J. Gurruchaga).

${ }^{117} \mathrm{La}$ fecha de la carta a Sapor resulta incierta, pero, por su contenido, parece ser de 324, inmediatamente posterior a la derrota de Licinio. Cfr. D. De Decker, «Sur le destinataire de la lettre au roi des perses (Eusèbe de Césarée, Vit. Const., IV, 9-13) et la conversion de de l'Armenie à la religion chrétienne», Persica 8 (1979), pp. 99-118.

${ }^{118}$ Euseb. Caes., VC, IV, 9 (Traducción de M. Gurruchaga).
} 
había abrazado la fe cristiana: «Amparado en la ayuda de este Dios, comenzando desde los confines del Océano, habiendo avanzado desde los extremos del Océano, levanté a todo el orbe hasta una firme esperanza de salvación, (...). A ese Dios respeto; mi ejército, consagrado a ese Dios, lleva sobre sus hombros su enseña (...). Al punto recibo yo de ahí la grata recompensa con victorias resonantes. (...) ${ }^{119}$. Constantino había profesado el cristianismo porque Dios le había procurado sus distintas victorias militares. Este testimonio venía acompañado de la descalificación del sacrificio sangriento como forma de culto: «De hinojos a Él invoco; huyo de toda sangre nauseabunda y de olores repugnantes y abominables $(. .).\rangle^{120}$. Este gesto, nunca antes visto en un príncipe, es igualmente consecuencia de la evolución de su política religiosa. Antes de la derrota de Licinio, Constantino se había hecho representar sacrificando en el arco que le dedicó el Senado en Roma. El documento trasladado por Eusebio aporta una información de gran valor histórico. El supuesto rechazo de Constantino de realizar el sacrificio tradicional relatado por Zósimo, con lo que el emperador quería expiar las ejecuciones de Crispo y Fausta por indicación de «un egipcio» no tuvo lugar nunca ${ }^{121}$. El príncipe había abominado de la práctica del sacrificio al menos dos años antes de las ejecuciones de los miembros de la familia imperial. Además, Constantino mostraba las razones por las que había dejado de sacrificar: reconocía en el Dios predicado por los cristianos a su protector. En realidad, es necesario cuestionarse la propia historicidad del episodio narrado por Zósimo. Constantino no tenía ninguna necesidad de provocar un incidente negándose a sacrificar en el transcurso de una ceremonia. Lo más probable es que no volviera a sacrificar después de 324. Por esas mismas fechas, Lactancio, que, como se ha visto, era una persona muy próxima a Constantino, hizo memoria del hecho publicando por segunda vez el tratado apologético Diuinae institutiones, en una dedicatoria al emperador recién convertido: «Constantine imperator maxime, qui primus Romanorum principum, repudiatis erroribus, maiestatem Dei singularis et ueri et cognouisti et honorasti» ${ }^{122}$. El literato señala expresamente que el emperador se había apartado de la religión tradicional, y confirma que había reconocido la existencia de un solo Dios único y verdadero, al que había honrado como tal. La actitud de Constantino hacia el cristianismo a partir 324 es muy diferente de la que había mostrado desde 314 hasta entonces, cuando, sin perjuicio de declararse siervo de Dios, practicaba otros cultos.

\footnotetext{
119 Euseb. Caes., VC, IV, 9 (Traducción de M. Gurruchaga).

${ }^{120}$ Euseb. Caes., VC, IV, 9 (Traducción de M. Gurruchaga).

121 Zos., II, 29. Sobre el origen de esta versión, que hace eco de una tradición oral, cfr. F. Paschoud, «Zosime 2, 29 et la version païenne de la conversion de Constantin», Historia 20 (1971), pp. 334-353; G. Marasco, «Giuliano e la tradizione pagana sulla conversione di Costantino», Rivista di Filologia e di Istruzione Classica 122 (1994), pp. 340-354; F. Paschoud, «Ancora sul rifiuto di Costantino di salire al Campidoglio», Costantino ..., G. Bonamente y F. Fusco, eds., II, pp. 737-748; Idem, «Zosime et Constantin. Nouvelles controverses», Museum Helveticum 54 (1997), pp. 9-28; A. Baldini, «Una confutazione ..., pp. 217-241.

${ }^{122}$ Lact., Diu. Inst. I, 1. Sobre la cronología y autoría de esta dedicatoria, cfr. E. Heck, Die dualistischen Zusätze und die Kaiserreden bei Lactantius. Untersuchungen zur Textgeschichte der «Diuinae Institutiones» und der Schrift «De opificio Dei». Heidelberg, 1972; E. d. P., Digeser, «Lactantius ..., pp. 33-52; Ch. M. Odahl, Ch. M., Constantine and the Christian Empire, London, 2004, p. 124.
} 
También del año 324, aunque algo posterior, debe de ser la «Carta a los ciudadanos orientales», igualmente citada por Eusebio en la biografía del emperador. En ella, Constantino invocaba a Dios diciendo: «Porque yo amo sinceramente tu nombre, respetando la fuerza que con muchas pruebas has dado en manifestar, y has hecho más sólida mi fe»» ${ }^{123}$. La carta a los provinciales de Palestina y la destinada a los orientales anunciaban la conversión a los ciudadanos romanos, en tanto que la carta a Sapor lo hacía fuera de las fronteras del Imperio.

La expresión de la fe cristiana vuelve a aparecer en el discurso dirigido «a la asamblea de los santos» (Oratio ad sanctorum coetum), cuyos destinatarios eran probablemente los participantes en el concilio de Nicea en el año 325. El texto editado por Eusebio tuvo distintas redacciones, posiblemente en lengua latina, y la primera de ellas fue inmediatamente posterior a la derrota de Majencio ${ }^{124}$. En el texto en cuestión, Constantino declaraba las razones de su adhesión profesa al cristianismo. Cristo le había librado de los males y mostrado una enseñanza que le procuraba la protección y salvación personal a él y a todos los que estuvieran dispuestos a obtenerla. Dice así un pasaje del discurso: «Cristo, Dios y Salvador: realizamos esta acción de gracias, magnífica providencia del magno Padre, que libras de los males y enseñas una doctrina felicísima $(. .).\rangle^{125}$. Dios ha sido el autor de sus sucesivas victorias bélicas, pues señala: « ¿Acaso no es Dios la causa de mis actos de valor?» "26. Dios también le había procurado los fundamentos de su actividad como legislador: «Dios prescribe las leyes de la justicia, y les hace ser similares a Él a quienes que merecieron ser sus discípulos» ${ }^{127}$. El reconocimiento de Dios como Salvador eficaz a través de su experiencia personal le había llevado al emperador a requerir de los obispos que le procuraran el favor divino. El planteamiento que presenta Constantino en la Oratio ad sanctorum coetum es muy similar al que aparece en el Edicto de Galerio y en tratado de Milán: los cristianos debían rogar por el príncipe para beneficio de todo el Imperio. La diferencia que hay entre el discurso y las leyes es la certeza que muestra el emperador de contar con el favor divino, que no se limita a los beneficios terrenos, sino también al don de la inmortalidad:

«Todos los hombres saben que estas manos deben ofrecer el servicio a Dios con fe pura y sincera, $y$, uniendo a la obra de sus manos las preces y las súplicas, (...). Vieron las luchas y fueron espectadores del combate, cuando la providencia de Dios dio la victoria al Pueblo. Los que observan la piedad, deben dar gracias al Salva-

\footnotetext{
${ }^{123}$ Euseb. Caes., VC, II, 55, 2 (Traducción de M. Gurruchaga).

${ }^{124}$ Sobre las distintas redacciones y su cronología, cfr. R. Cristofoli, Costantino e l'Oratio ad sanctorum coetum, Napoli, 2005. Según Pizzani y Barnes, el discurso fue pronunciado en Nicomedia en 325 y, de acuerdo con Bleckmann, en 328. Cfr. U. Pizzani, «Costantino e l'Oratio ad Sanctorum Coetum», Costantino ..., G. Bonamente y F. Fusco, eds., II, pp. 791-822; Br. Bleckmann, «Ein Kaiser als Prediger: Zur Datierung der konstantinischen «Rede an die Versammlung der Heiligen», Hermes 125 (1997), pp. 183-202; T. D. Barnes, Constantine ..., pp. 114-119.

${ }^{125}$ Or. ad sanct. coet., XI.

${ }^{126}$ Or. ad sanct. coet., XXVI.

127 Or. ad sanct. coet., XI.
} 
dor de todos, por nuestra salud y la suya propia y por el provecho de los asuntos públicos: que nos hagan propicio a Cristo con santos ruegos y continuas súplicas. (...) Éste es, en efecto, el guerrero invicto, el valedor de los justos, el mejor juez, el general de la inmortalidad y dador de vida eterna» ${ }^{128}$.

Constantino no era miembro de la comunidad de fieles. Su religiosidad tenía, por consiguiente, unos rasgos muy singulares. Eusebio de Cesarea, en su obra conocida como De laudibus Constantini, declara que el emperador tenía una relación personal con Dios $^{129}$. Dios se comunicaba con él por medio de visiones. Dice así el obispo de Cesarea: «(...) su visión divina, a ti mismo revelada, te ha revelado y dado a conocer lo que estaba escondido de lo sagrado, (...)» ${ }^{130}$. Y más adelante, añade: «De hecho, tú mismo, (...) podrías relatarnos las muchísimas manifestaciones de tu Salvador, sus muchas apariciones en sueños» ${ }^{131}$. Constantino era el varón elegido por Dios, por sus singulares virtudes, para llevar a cabo sus planes salvíficos. Después de la última guerra con Licinio, había mostrado a los ciudadanos en Constantinopla el «signo salvifico» (se presume que era el crismón), que representaba la protección divina sobre el príncipe y el Imperio ${ }^{132}$. Además, la protección de Dios sobre el emperador quedaba de manifiesto en «la ayuda en la guerra, la destrucción de los enemigos y de los conjurados, (...) la premonición de las cosas futuras, (...) el ejercicio del poder, la administración de los ejércitos (...) y las leyes útiles para la vida» ${ }^{133}$. En realidad, la religión cristiana que profesaba Constantino se asemejaba en muchos aspectos a los cultos tradicionales que abandonó paulatinamente a lo largo de su carrera imperial. El emperador reconoció el cristianismo como su religión personal. Por ello, beneficiaba a la Iglesia y a sus fieles porque de ese modo se aseguraba la victoria militar y la protección personal. De sus muestras de piedad esperaba una retribución. Así lo indica Eusebio: «Y por esto (...) aumenta su (...) estirpe y refuerza el trono del imperio por largos años, dando a sus hijos valerosos, a la familia y a su descendencia los frutos de la virtud» ${ }^{134}$.

Constantino, sin embargo, no estaba bautizado, luego no participaba en las ceremonias litúrgicas. Según Eusebio, sus actos de piedad se concretaban en rogar a Dios noche y día en las estancias del palacio imperial ${ }^{135}$. Hizo construir edificios de culto cristiano $^{136}$. Recibía a los miembros del clero en el palacio para hablar de religión y

\footnotetext{
128 Or. ad sanct. coet., XXVI (Traducción del autor).

129 Sobre la composición de la obra, cfr. T. D. Barnes, «Two Speeches by Eusebius», Greek, Roman and Byzantine Studies 18 (1977) 4, pp. 341-345; P. Maraval, «Sur un discours d'Eusèbe de Césarée (Louanges de Constantin, XI-XVIII)», Revue des Études Augustiniennes 43 (1997), pp. 239-241, n. 3; M. Amerise, Eusebio di Cesarea. Elogio di Costantino. Discorso per il trentennale. Discorso regale. Discorso regale. Introduzione, traduzione e note, Milano, 2005, pp. 16-25.

${ }^{130}$ Euseb. Caes., De laud. Const., XI, 1.

131 Euseb. Caes., De laud. Const., XVIII, 1.

132 Euseb. Caes., De laud. Const., IX, 9. 19.

133 Euseb. Caes., De laud. Const., XVIII, 3.

134 Euseb. Caes., De laud. Const., IX, 17.

135 Euseb. Caes., De laud. Const., V, 5; IX, 10.

136 Euseb. Caes., De laud. Const., IX, 12-16. Sobre estos edificios, cfr. J. Bardill, Constantine ..., pp. 230-259.
} 
fomentar la difusión del cristianismo ${ }^{137}$. En un caso, al menos, realizó una visita al lugar de la Ascensión, que bien puede calificarse de acto de peregrinación ${ }^{138}$. Además, fomentó que algunos miembros de su familia ya bautizados exhibieran gestos de devoción cristiana convencional, como era la veneración de los mártires. Constantina, hermana del emperador, construyó a sus expensas una iglesia dedicada a la mártir romana Santa Inés. Lo celebró Optaciano Porfirio en un caligrama, que cierra su colección publicada en 326 en homenaje a Constantino. Como informa la misma composición, la erección de la basílica tuvo un declarado propósito polémico, pues trataba de superar a los templos paganos en esplendor ${ }^{139}$. Por su parte, Elena, madre del emperador, mostró singular devoción hacia algunos mártires. Se hizo enterrar en Roma, junto a la basílica de los santos Pedro y Marcelino, a quienes debía de venerar ${ }^{140}$. Además, era devota del mártir Luciano, formador de Arrio, cuyas reliquias se hallaban en la ciudad bitinia de Drépanum, luego llamada por Constantino Helenópolis ${ }^{141}$.

\section{EL BAUTISMO DE CONSTANTINO}

La actitud de Constantino hacia el cristianismo cambió de nuevo poco antes de su muerte, cuando decidió ingresar en la comunidad de los fieles recibiendo el bautismo. Eusebio de Cesarea, en la biografía de Constantino que escribió poco después de su muerte, refiere pormenorizadamente las circunstancias en las que fue bautiza$\mathrm{do}^{142}$. Pero Eusebio no fue testigo presencial de los hechos narrados, aunque estaba bien informado, lo que aprovechó para tomarse algunas licencias en aras del propósito de su biografía del emperador: demostrar que Constantino había sido el brazo de Dios sobre la tierra, siendo su imperio una perfecta imitación (mímesis) del reino celeste. Esto no significa que sea falsa toda la información que procura Eusebio. Para comenzar, es verosímil el relato desde su comienzo, pues señala, al igual que otros textos, que el emperador estaba organizando una campaña contra los persas, que habían atacado las fronteras romanas ${ }^{143}$. Invocó la intercesión de los titulares de la basílica de los Santos Apóstoles de Constantinopla, a juicio de Eusebio, para beneficio de su alma. Por entonces empezó a sentir la proximidad de la muerte y ordenó que dispusieran el interior de la iglesia para su sepultura, junto a los cenotafios apostólicos ${ }^{144}$. De acuerdo con el obispo cesariota, la debilidad corporal, a la que no habían dado re-

\footnotetext{
${ }^{137}$ Euseb. Caes., De laud. Const., II, 5.

138 Euseb. Caes., De laud. Const., IX, 17.

139 Opt. Porf., XXXI: Constantina Deum uenerans Christoque dicata / omnibus impensis deuota mente paratis / (...) sacraui templum uictricis uirginis Agnes, / templorum quod uincit opus terrenaque cuncta, (...).

140 J. Guyon, Le cimitière aux deux lauriers. Recherches sur les catacombes romaines, Rome, 1987.

${ }^{141}$ Hieron. Strid., CCLXXVI Olymp. XXI; Philost., HE, Fr. XII-XIII; Pasch. 527. Cfr. J. W. Drijvers, Helena..., p. 10.

${ }^{142}$ Euseb. Caes., VC, IV, 62.

${ }^{143}$ Euseb. Caes., VC, IV, 57; Eutrop., X, 8, 2; Festus, Breu, XXVI; Hieron. Strid., Chron., CCLXXVIII Olymp. XXXI; Amm. Marc., XXV, 4, 23; Philostorg., HE, III, 1.

144 Euseb. Caes., $V C$, IV, 60.
} 
medio los baños terapéuticos, le hizo abandonar Constantinopla, para llegar a Drépanum, a modo de peregrinación, para venerar las reliquias conservadas en la ciudad. No parece, sin embargo, que la razón de dejar la cura de baños en Constantinopla fuera esa: Sócrates afirma -y parece confirmarlo Sozomeno- que el motivo del viaje a Drépanum no fue la visita de la iglesia martirial, sino la búsqueda de otros baños termales que remediaran sus males ${ }^{145}$. Cuando advirtió que los recursos naturales no podían curarle, recurrió a la religión. Debió de ser entonces cuando tomó la decisión de bautizarse, por si podía salvar su vida, rogando en la basílica de Drépanum. Allí, como narra Eusebio, después de haber confesado sus pecados y expresado su arrepentimiento, recibió la imposición de manos, rito con el que ingresó en el catecumenado ${ }^{146}$. El relato de Eusebio, complementado con la versión de Sozomeno, permite advertir que Constantino, viéndose en peligro de muerte, persiguió prolongar su vida mediante la práctica de la devoción y de su inicio en los sacramentos. Desplazado de Drépanum, en un suburbio de Nicomedia (Ancirona, por lo que señala Jerónimo), hizo llamar a obispos para que le bautizaran ${ }^{147}$. Recibió la instrucción mínima que exigía la disciplina canónica y, en palabras de Eusebio, los obispos presentes «le hicieron tener parte en los sagrados misterios» ${ }^{148}$. A continuación, muy enfermo ya, el emperador se revistió del alba, acto al que siguió un gesto muy singular: no quiso vestir de nuevo la púrpura ${ }^{149}$. Según Eusebio, esta decisión obedecía a que el bautismo impedía el ejercicio del imperio. No parece que fuera así: la disciplina canónica establecía que los recién bautizados debían llevar el alba durante siete días ${ }^{150}$.

Cuarenta y tres años después, Jerónimo de Estridón ofreció otra versión del bautismo del emperador en su Chronica, elaborada a partir de fuentes distintas de Eusebio ${ }^{151}$. Dice el pasaje en cuestión así: Constantinus extremo uitae suae tempore $a b$ Eusebio Nicomediensi episcopo baptizatus in Arrianum dogma declinat. (...) Constantinus cum bella pararet in Persas in Ancyrone uilla publica iuxta Nicomediam moritur anno aetatis LXVI. (... $)^{152}$. Jerónimo precisa que la ceremonia tuvo lugar en Ancirona, identifica al presidente del oficio bautismal: el filoarriano Eusebio de Nicomedia, y, a este propósito, señala que el emperador había caído en el «dog-

\footnotetext{
145 Socr. Const., HE, I, 39; Sozom., HE, II, 34.

146 Euseb. Caes., $V C, \mathrm{IV}, 61$.

147 Hieron. Strid., Chron., CCLXXVIII Olymp. XXXI; Rufin. Aquil., HE, I, 11. Según Sócrates y Teodoreto, fue bautizado en la misma ciudad de Nicomedia, cfr. Socr. Const., HE, I, 39; Theod. Cyr., HE, I, 30. Cfr. D. Woods, «Where Constantine I die?», Journal of Theological Studies 47 (1997), pp. 531-536; R. W. Burgess, «Akuron or Proasterion: the Location and Circumstances of Constantine's Death», ibidem 50 (1999), pp. 153161.

${ }^{148}$ Euseb. Caes., VC, IV, 62 (Traducción de M. Gurruchaga). Sobre los ritos seguidos en el bautismo de Constantino, cfr. M. Amerise, Il battesimo di Costantino. Storia di una scomoda eredità, Stuttgart, 2005, pp. 43-50.

149 Euseb. Caes., $V C$, IV, 62.

${ }^{150}$ M. Amerise, Il battesimo ..., pp. 49-50.

151 M. Amerise, Il battesimo ..., pp. 74-75.

152 Hieron. Strid., Chron., CCLXXVIII Olymp. XXXI.

153 Sobre Eusebio de Nicomedia y su presencia en la corte imperial, cf. D. M. Gwynn, «Eusebius of Nicomedia: a “Court Bishop” for Constantine?», Studia Patristica 46 (2010), pp. 289-294.
} 
ma arriano» ${ }^{153}$. Pero Jerónimo se excedió en su celo niceno al atribuir al emperador una supuesta «caída» en el arrianismo ${ }^{154}$. La explicación más probable de que Constantino recibiera el bautismo de manos de Eusebio de Nicomedia no era de índole doctrinal: Eusebio bautizó al emperador porque era el obispo de la ciudad a cuya diócesis pertenecía Ancirona.

Constantino murió el día de Pentecostés de 337. Fue enterrado siguiendo el ritual cristiano entonces en uso en la basílica de los Santos Apóstoles de Constantinopla, en una ceremonia supervisada por su hijo Constancio ${ }^{155}$. Este hecho no impidió que el Senado de Roma decretara su relatio inter diuos, siguiendo los usos tradicionales ${ }^{156}$. Fueron dos ceremonias completamente diferentes, en su forma y significado, realizadas en lugares distintos: el funeral constantinopolitano fue el de un emperador cristiano; la relatio romana se ajustaba a la tradición religiosa augustea. En Constantinopla, sin embargo, donde se hallaba enterrado el emperador, su imagen colocada sobre la columna de pórfido era venerada con velas y súplicas, como correspondía a un soberano deificado ${ }^{157}$.

\section{CONCLUSIONES}

La adhesión de Constantino al cristianismo como religión personal es el resultado de un prolongado proceso de acercamiento a una religión, en principio, extraña a las tradiciones romanas. Cabe afirmar, con todo rigor conceptual, que Constantino se convirtió al cristianismo, aunque, también es preciso señalarlo, siguiendo distintos pasos y modelos de afiliación religiosa. Le condujo a ello el afecto hacia la doctrina cristiana, que presentaba al Dios único y verdadero como el más eficaz protector de quien ejercía el poder. Tal vez formó esta actitud receptiva hacia ella en sus más estrechos círculos familiares, pero el cálculo político se puede advertir en cada uno de sus manifiestos religiosos, cristianos o no. No parece que hubiera cristianos en su familia durante su infancia, aunque puede que, al menos, su padre tuviera buena opinión de ellos, aunque no se contara entre sus prosélitos. Por lo que dice el mismo Constantino, conoció personalmente a los primeros cristianos en Nicomedia, cuando Diocleciano promulgó sus medidas persecutorias, y debió de estar presente en algunos procesos contra ellos. Se mantuvo fiel a los cultos tradicionales hasta el año 312, cuando, al recibir una respuesta desfavorable de los harúspices que le acompañaban en su campaña contra Majencio en la víspera de la batalla de Puente Milvio, declaró que había recibido la protección de un dios desconocido, sincrético y henoteísta.

\footnotetext{
${ }^{154}$ V. Aiello, «Costantino "eretico": difesa della "ortodossia" e anticostantinianesimo in età teodosiana», Accademia Romanistica Costantiniana, X, Perugia, 1995, pp. 55-83.

155 Euseb. Caes., VC, IV, 70-71; Socr. Const., HE, I, 40. Cfr. M. Humphries, «In Nomine Patris: Constantine the Great and Constantius II in Christological Polemic», Historia 46 (1997), pp. 448-464, esp. pp. 449-450.

${ }^{156}$ Eutrop., X, 8, 3. Véase también: A. Amici, «Diuus Constantinus: le testimonianze epigrafiche», Rivista Storica dell'Antichità 30 (2000), pp. 189-216.

${ }^{157}$ Philostorg., HE, Fr. XVII.
} 
Después de que dos textos normativos imperiales autorizaran el cristianismo (el Edicto de Galerio de 311 y el tratado de Milán de 313), con ocasión del estallido de la querella donatista en África, Constantino comenzó a dispensar un trato privilegiado a los cristianos, y, muy en particular, a los clérigos. Fue a propósito de la celebración del Concilio de Arelate en 314, que pretendía resolver el cisma de la Iglesia africana, cuando declaró en una carta oficial ser un siervo de Dios. Por entonces, cuando Lactancio elaboró su particular versión de la batalla de Puente Milvio, en la que Cristo pasaba a ser el protector del emperador. Pero Constantino no se había bautizado: reconocía la protección de Cristo, sin impedimento de observar los ritos consuetudinarios.

Las tres contiendas civiles contra Licinio, le hicieron aferrarse a la tradición religiosa romana. Sin embargo, vencido éste en 324, buscando el apoyo de las importantes comunidades cristianas de Oriente, fustigadas por su cuñado, acabó proclamando su fe en un solo Dios, único y supremo. Lo hizo en varios textos oficiales, que le sirvieron para presentarse como un emperador intelectual, con lo que acrecentó su prestigio entre los ciudadanos cultos. Finalmente, cuando se hallaba enfermo de muerte, la ineficacia de la medicina le urgió a tomar la decisión de recibir el bautismo, único posible remedio, sobrenatural, al peligro de muerte. Su incorporación sacramental a la Iglesia fortaleció su autoridad, como príncipe cristiano, y la de sus sucesores. No obstante, cabe señalar que, de acuerdo con todas las observaciones hechas, el concepto que llegó a formarse Constantino acerca del cristianismo como religión, principalmente utilitario, no difería mucho del que tenían sus contemporáneos sobre los cultos tradicionales. Si finalmente abandonó la observancia de la religión pública fue porque el cristianismo le había resultado más eficaz en la guerra, en la política y, en general, en la vida. 